\title{
Psychological Wellbeing among Permanent and Sahayak School Teachers
}

\author{
Vikas K. Rohit ${ }^{1 *}$
}

\section{ABSTRACT}

Aim of the research is to find out the Psychological Well being among Permanent and Sahayak School Teachers. So investigator selected two groups one is male school teachers and other is female school teachers, both groups have 160 peoples. In each group has 80 permanent school teachers other one groups has 80 Sahayak school teachers. Data were collected from Anand Taluka. Scale was use for data collection is personal datasheet and Psychological wellbeing scale developed by Bhogale and Prakash (1995), 2x2 factorial design was used and data were analysis by ' $F$ ' test. Result show, Sex had significant impact on psychological wellbeing. The female school teacher's psychological wellbeing is better than the male school teachers. There was no significant difference of psychological well being between permanent and sahayak school teachers. There was not significant interaction effect of Types of teachers and sex on Psychological well being.

Keywords: Psychological Wellbeing, Permanent Teacher, Sahayak Teacher, School

The concept of well-being originated from Positive Psychology. The shift from negative to positive psychology is a welcome change in the discipline. The focus of positive psychology is to study the improvement in the lives of individuals. Positive Psychology has emerged from the problem of the west. Thus it may be inferred that knowledge is culturally conditioned.

"A state of complete physical mental and social well-being and does not consist only of the obsess of disease of infirmity"

-World health organization (WHO) (1948)

"Psychological well-being as the general experience by individual that there will be positive outcome or circumstance"

-Adams, Bezner, \& Steinhardt (1997)

\footnotetext{
${ }^{1}$ PhD Research Scholar, Department of Psychology, S P University, V.V.Nagar, Gujarat, India

*Responding Author

(C) 2016 I V Rohit; licensee IJIP. This is an Open Access Research distributed under the terms of the Creative Commons Attribution License (http://creativecommons.org/licenses/by/2.0), which permits unrestricted use, distribution, and reproduction in any Medium, provided the original work is properly cited.
} 


\section{Psychological Wellbeing among Permanent and Sahayak School Teachers}

Psychological well-being is usually conceptualized as some combination of positive affective states such as happiness (the hedonic perspective) and functioning with Optimal effectiveness in individual and social life (the eudemonic perspective) (Deci \& Ryan 2008). As summarized by Huppert (2009, p.137) "Psychological well-being is about lives going well. It is the combination of feeling good and functioning effectively.” By definition therefore people with high PW report feeling happy, capable, and well supported, satisfied with life and so on; Huppert's (2009) review also claims the consequences of PW to include better physical health, mediate possibly by brain activation patterns, neuro- element effects and genetic factors.

Measurement of psychological well-being utilizes various instruments lacking any having gained dominance as a "gold standard".

\section{AIMS OF THE STUDY}

1. To study of the psychological well being among male and female teachers.

2. To study of the psychological well being among permanent and sahayak school teachers.

3. To study of the effect of interaction on psychological well being among the type of sex and teachers.

\section{Hypothesis:}

1. There is no difference between the psychological well being of the male and female teachers.

2. There is no difference between the psychological well being of the permanent and sahayak teachers.

3. There is no interaction effect of the psychological well being in the types of sex and types of teacher.

\section{METHODOLOGY}

\section{Research design:}

This research was adopted 2x2 factorial designs with 2 types of sex (male and female) and 2 types of teachers (permanent and sahayak)

\section{Sample:}

In this present study there are simple random sampling for this purpose Anand Taluka was selected. Sample taken from Various school of anand taluka Among this study 80 respondent of permanent school teachers 40 male and 40 female randomly selected as well as 80 respondent sahayak school teachers 40 male and 40 female selected. So in this study there are sample selected by simple random sampling method.

\section{Tools used:}

The following tools were used in the present study: 


\section{Psychological Wellbeing among Permanent and Sahayak School Teachers}

\section{Personal Data sheet:}

Certain personal information about respondents included in the sample of research is useful and important for research. Here also, for collecting such important information, personal data sheet was prepared. With the help of this personal data sheet, the information about types of teachers and types of sex was collected.

In this research following tools are used:

\section{Psychological well being scale:}

Psychological well-being questionnaire developed by Bhogale and Prakash (1995) was used to measure Psychological well-being. These are 28 sentences in this scale. All at the sentence had a two option "yes" or "no" belong two option can choose one option and marked by symbol $(\sqrt{ })$. In positive sentence 1 point for yes and 0 point for no. and in negative sentence 1 point for no and 0 point for yes. The test - retest reliability coefficient is $\mathbf{0 . 7 2}$ and internal consistency coefficient is 0.84. The author has reported satisfactory validity of the questionnaire.

\section{Statistical Analysis:}

In this study ' $F$ ' test was used for statistical analysis.

\section{RESULT AND DISCUSSION:}

\section{Psychological wellbeing with reference to teachers and sex:}

The main objective was to study whether Permanent and Sahayak male and female school teachers of differ in Psychological wellbeing. In this context, 3 null hypotheses (no.01to03) were constructed. For this purpose 2x2 factorial design was framed. To examine these null hypothesis statistical techniques of two way ANOVA was used. The results obtained are presented in table 1,2 and 3.

Table No.1, (N=160) Means and SDs of psychological wellbeing with reference to teachers and sex.

\begin{tabular}{|l|l|l|l|}
\hline \multicolumn{2}{|l|}{ Independent variable } & Male & Female \\
\hline \multirow{4}{*}{$\begin{array}{l}\text { Permanent } \\
\text { Teachers }\end{array}$} & Mean (M) & 18.79 & 18.36 \\
\cline { 2 - 4 } & SD & 5.06 & 5.34 \\
\cline { 2 - 4 } & $\mathrm{N}$ & 40 & 40 \\
\hline \multirow{3}{*}{ Sahayak Teachers } & Mean (M) & 16.12 & 16.73 \\
\cline { 2 - 4 } & SD & 3.83 & 4.39 \\
\cline { 2 - 4 } & $\mathrm{N}$ & 40 & 40 \\
\hline
\end{tabular}


Table No.2, (N=160), ANOVA summary of psychological wellbeing with reference to teachers and sex.

\begin{tabular}{|l|l|l|l|l|l|}
\hline Source of variance & $\begin{array}{l}\text { Sum of } \\
\text { squares }\end{array}$ & Df & $\begin{array}{l}\text { Mean sum of } \\
\text { squares }\end{array}$ & F & Sign. Level \\
\hline Sex & 149.92 & 1 & 149.92 & 7.007 & $0.01^{* *}$ \\
\hline Teachers & 0.282 & 1 & 0.282 & 0.013 & NS \\
\hline Sex \& Teachers & 8.840 & 1 & 8.840 & 0.42 & NS \\
\hline SSW(error) & 3319.18 & 156 & 21.277 & & \\
\hline SST & 3553.98 & 159 & & & \\
\hline & $* * \mathrm{p}>0.01, \mathrm{NS}=$ Not Significant & & \\
\hline
\end{tabular}

Table No. 3. (N=160) Difference between mean score of Psychological well being with reference to teachers and sex.

\begin{tabular}{|l|l|l|l|}
\hline Independent variable & N & Mean (M) & $\begin{array}{l}\text { Difference between } \\
\text { mean }\end{array}$ \\
\hline Male & 80 & 16.30 & \multirow{2}{*}{2.38} \\
\hline Female & 80 & 18.68 & \multirow{2}{*}{0.05} \\
\hline Permanent & 80 & 17.53 & \\
\hline Sahayak & 80 & 17.48 & \\
\hline
\end{tabular}

\section{Psychological well being with reference to Sex:-}

When $\mathrm{F}$ test was applied to check the impact of sex on psychological wellbeing among permanent and sahayak school teachers male and female, significant $F$ value was found. The $F$ value (Table No.2) is 7.007 which are statistically significant on level 0.01 . Table 3 reveals that the mean score of psychological wellbeing of male and female are 16.30 and 18.68 respectively and the difference of means (2.38) which is very high and not negligible. Hence the null hypothesis 1 was rejected and it was conclude that there was significant impact of sex of male and female school teachers on their psychological well being. 


\section{Psychological well being with reference to Teachers:-}

When F test was applied to check the impact of Teachers on psychological wellbeing among permanent and sahayak school teachers, No significant $F$ value was found. The F value (Table No.2) is 0.013 which is statistically not significant. Table 3 reveals that the mean scores of psychological wellbeing of permanent and sahayak teachers are 17.53 and 17.48 respectively and the difference between two is 0.05 are remarkable at they were not statistically significant. Hence the null hypothesis 2 was maintained and it was concluded that there was not any significant impact of permanent and sahayak school teachers of on their psychological wellbeing.

\section{Psychological well being with reference to interaction effect of sex and types of teachers:-}

When $\mathrm{F}$ test was applied to check the effect of sex and teachers on psychological wellbeing no significant impact was found. The $\mathrm{F}$ value (table no 2) is 0.42 which is statistically not significant. Hence the null hypothesis 3 was maintained and it was conclude that there was not significant interaction effect of type of sex and type of teachers on psychological wellbeing.

\section{CONCLUSION}

1. There is significant difference between the Psychological wellbeing of types of sex. The female school teacher's psychological wellbeing is better than the male school teachers.

2. There is no significant difference between the Psychological well being of permanent and sahayak school teachers.

3. There is no significant interaction effect between the sex and types of teachers.

\section{REFERENCES}

Bhogle, S. and Jay Prakash, I., (1995), Development of the psychological well-being questionnaire, Journal of Personality and Clinical studies, Vol. 11 (1 \& 2), pp. 5-9.

Broota, K.D., (1992), Experimental design in behavioural research, Wily, Western limited.

Carol D. Ryff and Corey Lee M.(1995) The Structure of Psychological Well-Being Revisited, vole 49, no.4,American psychological association.

Jadav, S. S., (2013). Lifestyle, Personality and Psychological well being: A comparative study of urban and rural educated unemployed people. Unpublished M.Phil Thesis. S. P. University, V.V.Nagar.

Winfield, Gill T k, Taylor A.W, Pilkington M, (2012) Psychological well-being and psychological distress, psychology of well being a Springer open journal. 